\title{
Morphological Behavior and Attachment of p19 Neural Cells to Root-End Filling Materials
}

\author{
Mohammad Ali Saghiri ${ }^{1}$, Kamal Asgar ${ }^{2}$, Morteza Daliri ${ }^{3,4}$, Mehrdad Lotfi5 ${ }^{5,6}$, \\ Abbas Delvarani ${ }^{7}$, PAyman MehrvarzFar ${ }^{7}$, AND Kasra Karamifar ${ }^{7}$ \\ ${ }^{1}$ Department of Dental Material, Dental Branch, Islamic Azad University, Tehran, Iran \\ ${ }^{2}$ Department of Dental and Biological Materials, University of Michigan, Michigan \\ ${ }^{3}$ National Institute for Genetic Engineering and Biotechnology, Karaj, Iran \\ ${ }^{4}$ National Institute of Immunology, New Delhi, India \\ ${ }^{5}$ Research Center for Pharmaceutical Nanotechnology, Tabriz University (Medical Sciences), Tabriz, Iran \\ ${ }^{6}$ Department of Endodontics, Dental Faculty, Tabriz University (Medical Sciences), Tabriz, Iran \\ ${ }^{7}$ Department of Endodontics, Dental Branch, Islamic Azad University, Tehran, Iran
}

\begin{abstract}
Summary: Some techniques and instruments like stereomicroscopy and confocal microscopy used for observing neural cells are too complicated and dependent on preparation and cell fixation methods. This may question the results of these methods. Though, we have used scanning electron microscopy on replicated specimens to observe p19 neural cells and their cellular extensions. This manuscript has shown the feasibility of using replica (indirect) method instead of direct methods for observing morphological characteristics of this high sensitive cell line. As neural cells are very sensitive to fixation solutions and processes, we have used replica mode and observed neural cells with a novel indirect method. We have used replica mode in this study to indirectly and noninvasively evaluate the state of p19 neural cells and their cellular extensions. SCANNING 32: 369-374, 2010. (C) 2010 Wiley Periodicals, Inc.
\end{abstract}

Key words: mineral trioxide aggregate, p19 neural stem cells, replica, scanning electron microscope

\footnotetext{
The work was done in the following departments and institutions: Department of Dental and Biological Materials, University of Michigan, MI; Department of Dental Material, Dental School, Islamic Azad University, Tehran, Iran; National Institute of Immunology, New Delhi, India.

Address for reprints: Mohammad Ali Saghiri, Department of Dental Material, Dental Branch, Islamic Azad University, Tehran, Iran

E-mail: saghiri@gmail.com
}

Received 9 September 2010; Accepted with revision 11 October 2010

DOI $10.1002 /$ sca. 20209

Published online 9 November 2010 in Wiley Online Library (wiley onlinelibrary.com)

\section{Introduction}

An ideal root-end filling material should have various properties such as easy manipulation, conductivity to create an apical seal, ability to promote periapical healing, no toxicity for the periradicular tissues, noncorrosiveness or electrochemical activity, and the ability to adhere to the root canal system in three dimensions (Gartner and Dorn 1992). These materials should be biocompatible because of their direct and prolonged contact with the periodontium and should permit healing of periradicular tissues via regeneration of cementum, periodontal ligament, and alveolar bone across the resected root-end surface (Fouad et al. 1993). Amalgam, composite resin, intermediate restorative material, Super EBA, glass-ionomer, polycarboxylate cements, Cavit, gutta-percha (GP) (Friedman 1991), and mineral trioxide aggregate (MTA) all have been used as root-end filling materials. Many studies have shown that MTA is one of the most tissue friendly retrofilling materials (Torabinejad et al. 1997; Koh et al. 1997; Camilleri et al. 2004).

The cytotoxicity of root-end filling materials has been tested on different cell lines such as fibroblasts, osteoblasts, kidney-cell line, and L-929 fibrosarcoma cells (Keiser et al. 2000). Determining the mitochondrial function (Keiser et al. 2000) and measuring the inhibition zone of cell growth (Bruce et al. 1993) are common methods of evaluating the toxicity of endodontic materials. These assays mostly measure the inhibition of cell replication or activity, and they do not measure the cell death directly. Some toxicity assays have measured actual cell death (Lobner 2000).

There are few studies on neurotoxicity of endodontic materials. It seems that the use of neural cells 
is more sensitive than other methods of biocompatibility evaluation (Asrari and Lobner 2003). Neurons, much more than fibroblasts, can provide a highly sensitive system which is susceptible to freeradical-mediated injury, metabolic insults, and environmental toxins (Mattson et al. 1995).

Root-end filling materials are in close contact with nerve endings and local nerves, which lack cell bodies found in cortical cultures. Death of neurons can result from damage to the neuronal processes in cortical cultures (Tecoma et al. 1989). In addition, one of the components of tissue regeneration that has sometimes been neglected is the neural supplement regeneration. There are limited studies on the effect(s) of white mineral trioxide aggregate (WMTA) on neural cells. The aim of this study was to evaluate the neurotoxicity of WMTA on p19 stem cells when exposed to different biological fluids.

\section{Materials and Methods}

P19 stem cells were obtained from Pasteur Institute (Pasteur Institute, Tehran, Iran). P19 cultures started from a frozen stock by thawing the cells rapidly at $37^{\circ} \mathrm{C}$ and were cultured in a standard medium consisting of $\alpha$-MEM (GIBCO BRL, Life Technologies, Grand Island, NY) supplemented with $7.5 \%$ calf serum (GIBCO BRL, Life Technologies), 5\% fetal serum (FCS) (GIBCO BRL, Life Technologies), and $100 \mathrm{U} / \mathrm{mL}$ penicillin-streptomycin. The cells were maintained at sub-confluency by being sub-cultured into tissue culture-grade dishes (Nunc, Roskilde, Denmark) every $48 \mathrm{~h}$ and then removed from the culture dishes by being treated with trypsin (GIBCO BRL, Life Technologies) to induce neurally differentiated p19 stem cells. The cells were plated at a density of $5 \times 10^{4} \mathrm{cell} / \mathrm{mL}$ in the medium supplemented with $0.3 \mathrm{mM}$ of retinoic acid (RA) (Sigma, St. Louis, MO) into $100 \mathrm{~mm}$ bacteriological-grade Petri dishes (Nunc) initially and grew as aggregates for 4 days. The medium was refreshed every $48 \mathrm{~h}$ during this period.

Twenty WMTA (Tooth-colored Formula, Dentsply, Tulsa Dental, Tulsa, OK) sachets were mixed separately with distilled water under aseptic conditions according to manufacturer's instructions and packed into 40 cylindrical polycarbonate tubes (Falcon Plastics, Div. of BioQuest, Oxnard, CA). A suitable micro-condenser (Hu-Friedy, Chicago, IL) was chosen and checked to ensure that the tip would fit the diameter and length of the cylindrical polycarbonate tubes with an inner diameter of $8 \mathrm{~mm}$ and a height of $10 \mathrm{~mm}$.

Four groups with ten specimens each were prepared. Each specimen was placed in a separate vial and stored at $37^{\circ} \mathrm{C}$ and $100 \%$ relative humidity for $24 \mathrm{~h}$ to ensure WMTA setting. Three wet pieces of gauze soaked in blood, deionized water (DW), and synthetic tissue fluid (STF), respectively, covered all the specimens in each group for $24 \mathrm{~h}$. Gauze pieces were replaced every $6 \mathrm{~h}$ with fresh ones to ensure a sufficient environment. In the fourth group, WMTA sachets were mixed with STF at a STF-to-powders ratio of 0.33 and prepared according to a previous study (Ratner et al. 2004). Ten tubes were filled with GP (Bifill System, VDW, Munich, Germany), and ten tubes were filled with zinc oxide-eugenol (ZOE) (Kemdent; Associated Dental Products Ltd, Wiltshire, U.K.). Finally, all the specimens were taken out of the polycarbonate tubes and stored separately under aseptic conditions.

After 4 days of RA treatment, the aggregates were plated onto tissue culture-grade dishes containing WMTA and GP tablets in a medium without RA and the culture continued for 10 days. GP tablets were fixed into culture dishes by Nickel Titanium (Ni-Ti) needles to ensure that GP was placed at the bottom of culture plates.

Immediately after the tablets were taken out of the tissue media, each tablet was placed in a Petri dish and cooled down to $-70^{\circ} \mathrm{C}$ at a rate of $10^{\circ} \mathrm{C} / \mathrm{min}$ (MDF-C8V1, Sanyo Electric Co., Japan). Petri dishes were placed on a tray and stored in a freezer at $-70^{\circ} \mathrm{C}$ for $24 \mathrm{~h}$.

Immediately after the tablets were retrieved from the freezer, a replica of each tablet was prepared using a resin (RepliSet-F1 $50 \mathrm{~mL}$ System, Struers, Denmark). The prepolymer was mixed with the curing agent, and placed without delay on each tablet. The tablets were kept for $20 \mathrm{~min}$ at room temperature so that the replicas would become cured. The peeled-off replicas were observed under a scanning electron microscope (SEM, Cambridge Instrument S360, Cambridge, England). Figure 1 shows the design of the experiment.

Each replica surface was sputter coated with gold and visualized under SEM at $15 \mathrm{kV}$ by a secondary detector. A grading system was developed with respect to the amount of cell attachment and their traces on the replica surface in each sample according to the following criteria:

1. None to slight $(0-25 \%)$.

2. Mild $(26-50 \%)$.

3. Moderate $(51-75 \%)$.

4. High (76-100\%).

Two investigators scored the amount of cell attachments in a blind manner according to the grading criteria. In case of discrepancies in the scores determined by the two investigators, a third investigator was asked to score the samples. 


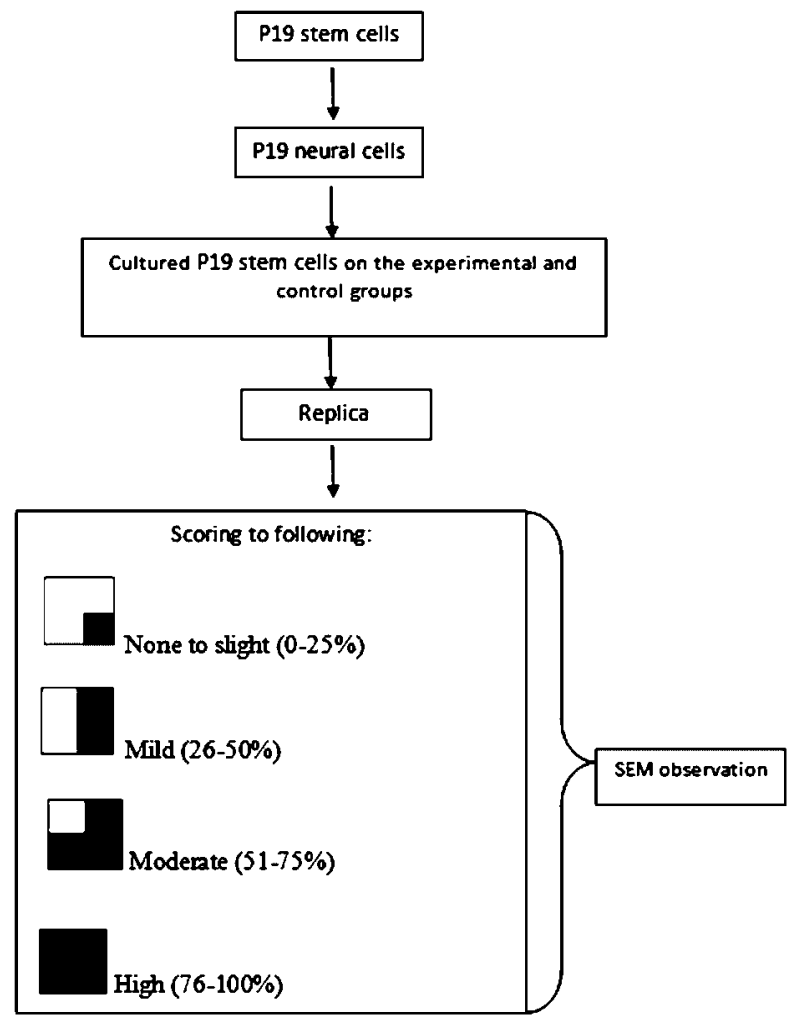

Fig 1. Flowchart of the experiment.

Finally, two similar scorings were considered as the final score.

ANOVA and a post hoc Tukey test were used for statistical analysis.

\section{Results}

The mean \pm standard deviations of the amount of cell attachment for WMTA exposed to blood, DW, and STF, and WMTA mixed with STF, ZOE, and GP were $3.5 \pm 0.52,1.0 \pm 0.00,2.7 \pm 0.67,1.5 \pm 0.52$, $1.0 \pm 0.00$, and $3.5 \pm 0.52$, respectively. ANOVA revealed significant differences among the groups $(p<0.0001)$ (Fig. 2). Post hoc Tukey test did not demonstrate any significant differences between WMTA exposed to blood and GP $(p=1.00)$, but there were significant differences between WMTA exposed to blood and other groups (Fig. 2).

SEM micrographs are displayed in Figure 3. The secondary detector (SE) detected a neuron structure, including the nucleus, cell body, axon, dendrite, and synapses in WMTA/B, and GP specimens. In addition, p19 cells in WMTA/B and GP groups grew normally and their morphology was comparable to that of the parent cell (Tanaka et al. 2003). Trace of NiTi needle is shown by $(\triangleright)$ in Figure 3(e). SEM micrographs revealed that uniformly differentiated p19 cells predominantly covered the surface of WMTA/B and GP groups. Consistent with the

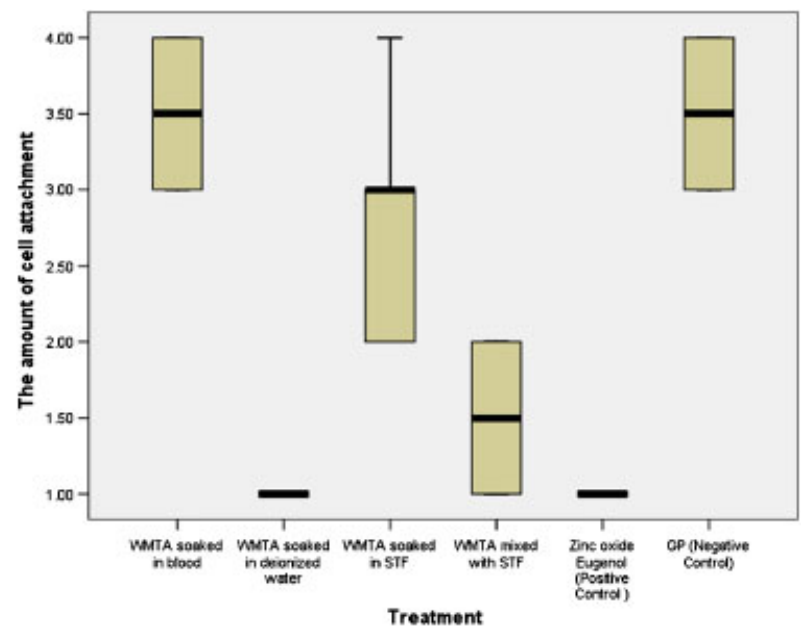

Fig 2. Mean amount of cells grade for materials.

morphological observation, dendrite fibers which emanate from the cell body and provide the receptive zones that receive activation from other neurons were clearly observed (Fig. 3(a) and (b)). In the WMTA/DW group the cells had disappeared. Differentiated p19 stem cells showed similar morphology to those observed in previous studies (Tanaka et al. 2003).

\section{Discussion}

Root-end filling materials may inadvertently be overextended beyond the root canal space and invade the surrounding periodontium and bone. The material introduced within such a sensitive anatomical space may mechanically or chemically affect the peripheral nerve fibers, such as the inferior alveolar nerve and neural cells (Gallas-Torreira et al. 2003), resulting in a series of complications such as paresthesia (Orstavik et al. 1983).

The quality and quantity of cell attachment, adhesion, and spreading on the root-end filling materials can be used as a criterion for evaluation and as an indicator of the materials' biocompatibility (Zhu et al. 2000). Cell attachment is one of the most sensitive methods for measuring toxicity. Different cells, such as MG-63 osteosarcoma cells (Koh et al. 1998), Saos-2 osteosarcoma cells (Zhu et al. 2000), human gingival fibroblasts, periodontal ligament fibroblasts (Bonson et al. 2004), human alveolar bone cells (Perinpanayagam et al. 2006), and cementoblast cell lines (Thomson et al. 2003), have been used for the evaluation of MTA biocompatibility.

P19 stem cells are the major cell lines available and can be used for evaluating neurotoxicity of different materials. A previous study (Khorasani et al. 2009) has shown the suitability and reliability of cultured p19 stem cell test for the evaluation of 


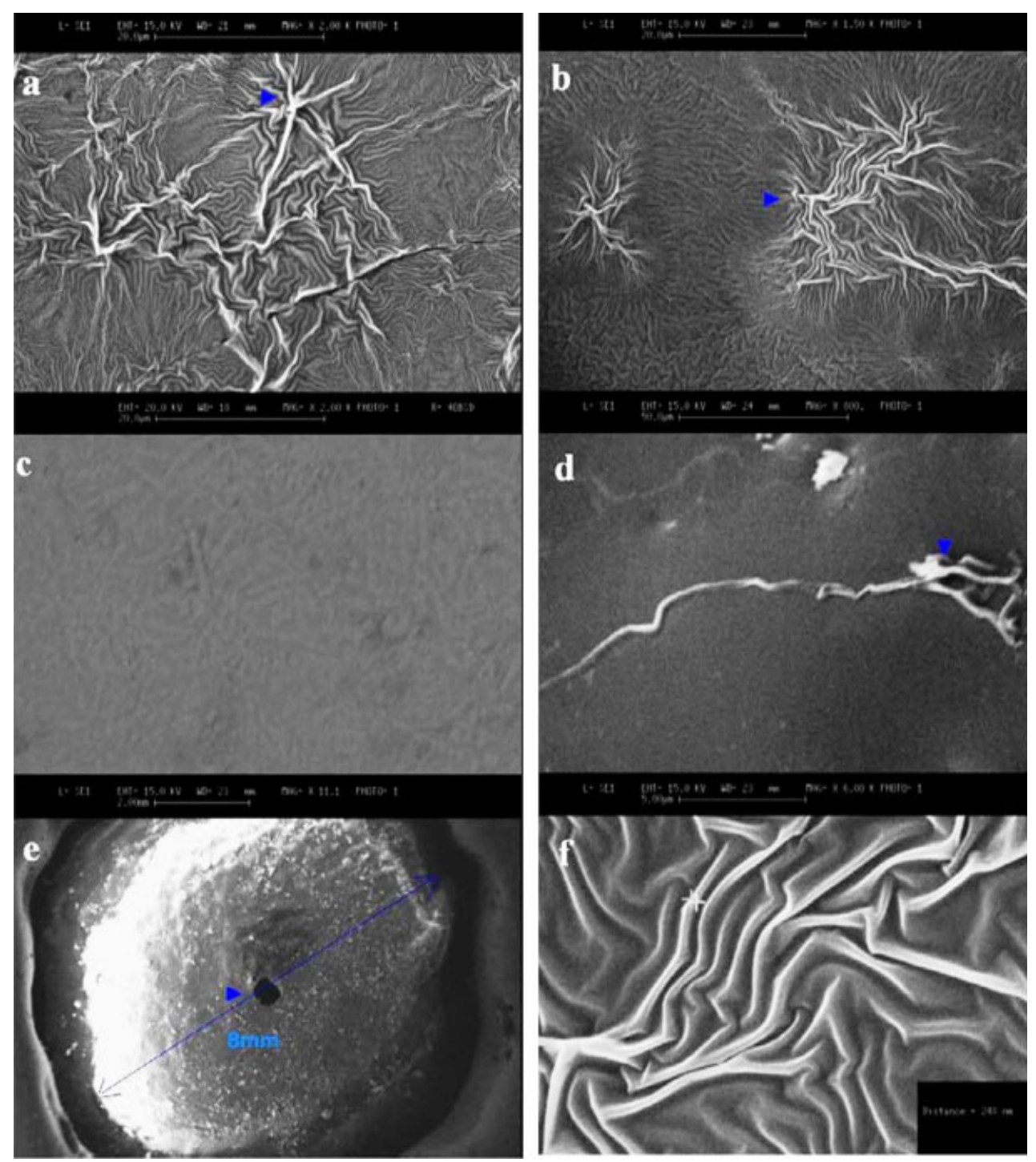

Fig 3. Scanning electron microscopy images of specimens which were exposed to WMTA/Blood $(\mathbf{a})(\times 2000)$, GP $(\mathbf{b})(\times 1500)$, and, WMTA/DW $(\mathbf{c})(\times 2000)$, WMTA/STF $(\mathbf{d})(\times 800)$, respectively, More Cells $(>)$ can be seen on the surface of WMTA exposed to blood; in addition, overview of replica impression on WMTA tablet, inner diameter (8 mm) and trace of NiTi $(\mathbf{D})$ can be seen on the surface $(\mathbf{e})(\times 11)$. Synapse formation $(+)$ in great detail $(\mathbf{f})(\times 6000)$ and Abnormal cells can be seen in WMTA with $\operatorname{STF}(d)$.

neurocompatibility, which is more sensitive than biocompatibility evaluation (Asrari and Lobner 2003). Like other neural cells, viable differentiated p19 stem cells exhibit dendritic and axonal parts, while loss of cell compartments reveals cell death, indicating neurotoxicity (Finley et al. 1996).

WMTA comes in contact with blood or tissue fluids when placed as root-end filling material; therefore, blood was selected to simulate clinical conditions, whereas STF was selected to simulate dentinal and tissue fluids. WMTA mixed with STF was selected to mimic placement of dry MTA as confirmed by some investigators (Budig and Eleazer 2008) that dry MTA can be adequately hydrated by moisture penetration into the root body in clinical settings.
In this study, the superior neurocompatibility of WMTA, when exposed to blood rather than STF, may be attributed to the production of a unique and more neurocompatible surface, resulting from the presence of different bio-active elements in blood rather than in STF, which affect WMTA surface. In addition, it has been reported that when MTA is placed upon tissues, some bio-active molecules may be produced (Tomson et al. 2007). WMTA itself may not be neurocompatible because the exposure of WMTA to DW produced the least neurocompatibility. DW was selected because it has no proteins, enzymes, or saturated ions.

The potential of blood to react with WMTA surface might produce a mechanical barrier against the solution's penetration, which limits the ability 
for exchanging any materials with surrounding tissues. The composition and surface texture of the root-end filling material have an influence on the morphology and cell attachments, reflecting the biocompatibility of the substratum (Balto and Al-Nazhan 2003). It seems that provision of bioactive elements by blood is an important factor involved in the differentiation of p19 stem cells in WMTA/Blood group.

GP and ZOE were selected as controls because they are generally considered biocompatible and nonbiocompatible root canal filling materials, respectively (Tani-Ishii and Teranaka 2003).

Anti-nociceptive effects of WMTA were evaluated. WMTA did not irritate nerve tissues and was more effective than eugenol in relieving orofacial nociceptive pain of formalin injection (Abbasipour et al. 2009). An investigation with osteoblast-like cells on MTA has found that MTA has low toxicity and does not inhibit cell growth but can suppress the differentiation of osteoblast-like cells (Nakayama et al. 2005). In contrast to our study, the experimental time interval in that study (Nakayama et al. 2005) was up to 3 days, which has been reported to be too short for rat bone marrow cells to be divided and converted to functional osteoblasts. Furthermore, the use of gray or white MTA has not been mentioned in that study. It is an established fact that some of the ingredients of white and gray MTA are not similar (Song et al. 2006).

Despite the significant differences between WMTA/STF, WMTA/DW and GP, the comparison of WMTA/B and GP showed no significant differences. These findings might be attributed to the creation of a layer on the surface of WMTA after being exposed to blood, which may prepare the surface to meet specific biocompatibility requirements such as morphology, wettability, and solubility (Ratner et al. 2004). MTA produces calcium hydroxide when mixed with water; therefore, when a mixture of MTA and water is exposed to tissue fluid, hydroxyapatite crystals (the major component of bone) are produced that cover the surface of MTA (Sarkar et al. 2005). Therefore, low neurotoxicity of WMTA in the presence of blood might be attributed to the formation of hydroxyapatite crystals on WMTA surface. Comparison between WMTA/STF and WMTA mixed with STF showed significant differences which can be explained by the ability of STF to release all of its major cationic components (Ratner et al. 2004), leading to an influence on neural cells.

Neural cells are very sensitive to fixation solutions and processes. Some techniques and instruments such as stereomicroscopy and confocal microscopy (Ugel et al. 2004) used for observing
M. A. Saghiri et al:: Morphological behavior

neural cells are dependent on preparation and cell fixation methods which are too complicated (Fedoroff and Richardson 2001). A novel indirect method by scanning electron microscopy on replicated specimens was used to observe p19 neural cells and their cellular extensions. In addition, this study demonstrated feasibility and suitability of replica technique to observe p19 neural cells morphology and behavior.

\section{Conclusion}

It can be concluded that replica technique is suitable for studying morphological behavior and attachment of p19 neural stem cells. Further studies may prove the suitable of this technique for studying other cell lines morphological behaviors. Also, biological systems react to the surface characteristics of the materials in contact with it; therefore, exposure of WMTA to blood may alter its surface properties, making it more neurocompatible. In addition, the exposure of WMTA to blood during reparative usage of WMTA may enhance its neurocompatibility.

\section{References}

Abbasipour F, Rastqar A, Bakhtiar H, Khalilkhani H, Aeinehchi M, et al.: The nociceptive and anti-nociceptive effects of white mineral trioxide aggregate. Int Endod $J$ 42, 794-801 (2009).

Asrari M, Lobner D: In vitro neurotoxic evaluation of rootend-filling materials. $J$ Endod 29, 743-746 (2003).

Balto H, Al-Nazhan S: Attachment of human periodontal ligament fibroblasts to 3 different root-end filling materials: Scanning electron microscope observation. Oral Surg Oral Med Oral Pathol Oral Radiol Endod 95, 222-227 (2003).

Bonson S, Jeansonne BG, Lallier TE: Root-end filling materials alter fibroblast differentiation. J Dent Res 83, 408-413 (2004).

Bruce GR, McDonald NJ, Sydiskis RJ: Cytotoxicity of retrofill materials. J Endod 19, 288-292 (1993).

Budig CG, Eleazer PD: In vitro comparison of the setting of dry ProRoot MTA by moisture absorbed through the root. J Endod 34, 712-714 (2008).

Camilleri J, Montesin FE, Papaioannou S, McDonald F, Pitt Ford TR: Biocompatibility of two commercial forms of mineral trioxide aggregate. Int Endod J 37, 699-704 (2004).

Fedoroff S, Richardson A: Protocols for Neural Cell Culture $3 r d$ ed., Humana Press, Totowa, NJ, 1-12, 219-228 (2001).

Finley MF, Kulkarni N, Huettner JE: Synapse formation and establishment of neuronal polarity by P19 embryonic carcinoma cells and embryonic stem cells. J Neurosci 16, 1056-1065 (1996).

Fouad AF, Walton RE, Rittman BR: Healing of induced periapical lesions in ferret canines. $J$ Endod 19, 123-129 (1993).

Friedman S: Retrograde approaches in endodontic therapy. Endod Dent Traumatol 7, 97-107 (1991). 
Gallas-Torreira MM, Reboiras-López MD, GarcíaGarcía A, Gándara-Rey J: Mandibular nerve paresthesia caused by endodontic treatment. Med Oral 8, 299-303 (2003).

Gartner AH, Dorn SO: Advances in endodontic surgery. Dent Clin North Am 36, 357-378 (1992).

Keiser K, Johnson CC, Tipton DA: Cytotoxicity of mineral trioxide aggregate using human periodontal ligament fibroblasts. J Endod 26, 288-291 (2000).

Khorasani MT, Mirzadeh H, Talebi A, Irani S, Daliri M: Tubular scaffold design of poly (L-lactic acid) for nerve tissue engineering: preparation, characterization, and in vitro assay. Iran Polym J 18, 297-306 (2009).

Koh ET, McDonald F, Pitt Ford TR, Torabinejad M: Cellular response to mineral trioxide aggregate. $J$ Endod 24, 543-547 (1998).

Koh ET, Torabinejad M, Pitt Ford TR, Brady K, McDonald F: Mineral trioxide aggregate stimulates a biological response in human osteoblasts. $J$ Biomed Mater Res 37, 432-439 (1997).

Lobner D: Comparison of the LDH and MTT assays for quantifying cell death: validity for neuronal apoptosis? J Neurosci Methods 96, 147-152 (2000).

Mattson MP, Barger SW, Begley JG, Mark RJ: Calcium, free radicals, and excitotoxic neuronal death in primary cell culture. Methods Cell Biol 46, 187-216 (1995).

Nakayama A, Ogiso B, Tanabe N, Takeichi O, Matsuzaka $\mathrm{K}$, et al.: Behaviour of bone marrow osteoblast-like cells on mineral trioxide aggregate: morphology and expression of type I collagen and bone-related protein mRNAs. Int Endod $J$ 38, 203-210 (2005).

Orstavik D, Brodin P, Aas E: Paraesthesia following endodontic treatment: survey of the literature and report of a case. Int Endod $J$ 16, 167-172 (1983).

Perinpanayagam $\mathrm{H}$, Martin $\mathrm{T}$, Mithal V, Dahman M, Marzec N, et al.: Alveolar bone osteoblast differentiation and Runx 2/Cbfa 1 expression. Arch Oral Biol 51, 406-415 (2006).
Ratner BD, Hoffman AS, Schoen FJ, Lemons JE: Biomaterials Science: An Introduction to Materials in Medicine 2 nd rev. ed., Elsevier Academic Press, London, 40-57 (2004).

Sarkar NK, Caicedo R, Ritwik P, Moiseyeva R, Kawashima I: Physicochemical basis of the biologic properties of mineral trioxide aggregate. J Endod 31, 97-100 (2005).

Song JS, Mante FK, Romanow WJ, Kim S: Chemical analysis of powder and set forms of Portland cement, gray ProRoot MTA, white ProRoot MTA, and gray MTAAngelus. Oral Surg Oral Med Oral Pathol Oral Radiol Endod 102, 809-815 (2006).

Tanaka K, Kitagawa Y, Kadowaki T: Misexpression of mouse porcupine isoforms modulates the differentiation of P19 embryonic carcinoma cells. Cell Biol Int 27, 549-557 (2003).

Tani-Ishii N, Teranaka T: Clinical and radiographic evaluation of root-canal obturation with obtura II. $J$ Endod 29, 739-742 (2003).

Tecoma ES, Monyer H, Goldberg MP, Choi DW: Traumatic neuronal injury in vitro is attenuated by NMDA antagonists. Neuron 2, 1541-1545 (1989).

Thomson TS, Berry JE, Somerman MJ, Kirkwood KL: Cementoblasts maintain expression of osteocalcin in the presence of mineral trioxide aggregate. $J$ Endod 29, 407-412 (2003).

Tomson PL, Grover LM, Lumley PJ, Sloan AJ, Smith AJ, et al:: Dissolution of bio-active dentine matrix components by mineral trioxide aggregate. J Dent 35, 636-642 (2007).

Torabinejad M, Pitt Ford TR, McKendry DJ, Abedi HR, Miller DA, et al.: Histologic assessment of mineral trioxide aggregate as a root-end filling in monkeys. $J$ Endod 23, 225-228 (1997).

Ugel H, Bewersdorf J, Jakobs S, Engelhardt J, Storz R, et al.: Combining 4Pi excitation and detection delivers sevenfold sharpersections in confocal imaging of live cells. Biophys J 87, 4146-4152 (2004).

Zhu Q, Haglund R, Safavi KE, Spangberg LS: Adhesion of human osteoblasts on root-end filling materials. $J$ Endod 26, 404-406 (2000) 